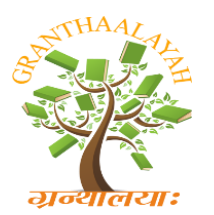

INTERNATIONAL JOURNAL OF RESEARCH -

GRANTHAALAYAH

A knowledge Repository

Management

\title{
A STUDY ON CAREER SATISFACTION OF ARTS AND SCIENCE COLLEGE STUDENTS WITH SPECIAL REFERENCE TO KANYAKUMARI DISTRICT
}

\author{
M. Sugin Raj ${ }^{* 1}$ \\ ${ }^{* 1}$ Assistant Professor, Malankara Catholic College-Mariagiri, INDIA
}

\begin{abstract}
A Career is the sequence and variety of occupations (paid and Unpaid) which one undertakes throughout a life time. More broadly 'Career' includes life roles, leisure activities, learning and work. This study examines the Arts and Science college students' career selections, career satisfactions, the influences of career guidance classes in career selection, students' confident level about their selected career and factors determining the career selection. A Survey research design was adopted to obtain data from 100 respondents from various college arts and science students. The results of the study reveals that $68 \%$ of students are satisfied on their selected career, $82 \%$ of respondents are have confident on their selected career and career selection has been influenced by various factors such as job vacancy, goodwill, passion on career, status, society and own interest. The study concludes that career selection is the primary responsibility of students based on their won wishes. Career guidance classes can be offered to all school students to select suitable career according to the wish of students.
\end{abstract}

Keywords:

Career, career selection, career guidance class.

Cite This Article: M. Sugin Raj, "A STUDY ON CAREER SATISFACTION OF ARTS AND SCIENCE COLLEGE STUDENTS WITH SPECIAL REFERENCE TO KANYAKUMARI DISTRICT" International Journal of Research - Granthaalayah, Vol. 4, No. 3: SE (2016): 31-36.

\section{INTRODUCTION}

Career selection is one of many important choices students will make in determining future plans. This decision will impact them throughout their lives. The essence of who the student is will revolve around what the student wants to do with their life-long work. Every student carries the unique history of their past and this determines how they view the world. That history created, in part by the student's environment, personality, and opportunity, will determine how students make career choices. It then follows that how the student perceives their environment, personality, and opportunity also will determine the career choices students make. 


\section{FACTORS IN CAREER CHOICE}

The first factor in career choice, environment may influence the career students choose. For example, students who have lived on an island may choose a career dealing with the water, or they may choose to leave the island behind, never to have anything to do with water again. Maybe someone in the student's life has made a significant impact or impression, leading to a definite career choice. Parents' educational background may influence student views on whether or not to continue their education. Someone they saw on television may have influenced the student, or parents may have demanded that they assume a family business. These are various environmental factors that would lead a student to a chosen career.

How students have seen themselves in a role in which personality is a determining factor may influence a chosen career. Some careers demand that you have the personality to match the qualities of the occupation. A student's personality must be a self-motivated type, as to investigate career possibilities from early on in their lives, and not the procrastinating type that waits until they are compelled to decide. Students must take seriously the role grades play in limiting opportunities in the future.

Opportunity is the third factor that has shaped career choices for students. Opportunity may influence how students have perceived their future in terms of the reasonable probability of a future in particular career fields. The issue of poverty has played an important determining role in the opportunities available to all. The income level of high school families may determine what career a student chooses during a specific time in the student's life; choices that will determine a large part of that student's future. Some students will have to budget education according to their personal income.

\section{OBJECTIVES}

1) To find out the factor determining the career selection

2) To identify the students satisfaction level on their respective course

3) To investigate the influences of career guidance classes to choose the course

4) To analyze the students confident level about their career.

\section{METHODOLOGY}

\section{COLLECTION OF DATA}

The research has used random sampling to collect the data from 100 respondents who are studying in colleges at various disciplines and used structured questionnaire as a research instrument tool which consists of open ended questions, multiple choices questions and also used five point licker scale test in order to get data. Thus, questionnaire is the data collection instrument used in the study. All the questions in the questionnaire are organized in such a way that to relevant information that is needed for the study. Secondary data has been collected from various articles, journals projects and online resources. 


\section{TOOLS AND TECHNIQUES}

The analysis of data in a general way involves a number of closely related operations, which are performed with the purpose of summarizing the collected data and organizing them in such a manner that they answer the research questions. In this research, the researcher used percentage method for data analysis and various pictorial representations such as graphs ,charts and diagrams used to interpret the data

\section{ANALYSIS AND INTERPRETATION}

\section{1) Opinion about career guidance classes:}

\begin{tabular}{|l|l|l|l|}
\hline S. No & Sources & No of respondents & \% of respondents \\
\hline 1 & Very useful & 54 & 54 \\
\hline 2 & Useful & 12 & 12 \\
\hline 3 & Neutral & 8 & 8 \\
\hline 4 & Not useful & 26 & 26 \\
\hline Total & & 100 & 100 \\
\hline
\end{tabular}

Source: Primary data

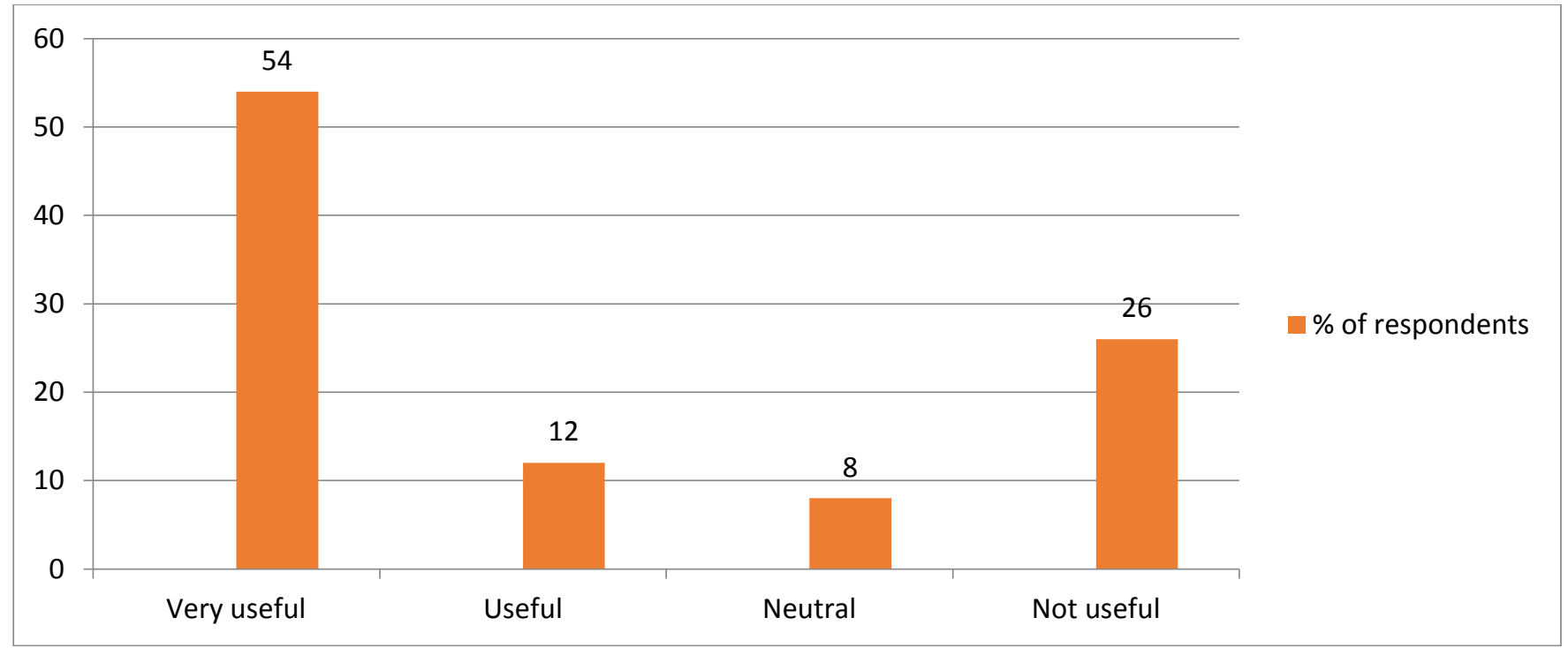

This table and charts shows that career guidance classes help $76 \%$ students to select their career. $26 \%$ respondents say that career guidance classes not influenced them to select their career.

\section{2) Factors influencing college selection:}

\begin{tabular}{|l|l|l|l|}
\hline S. No & Source & No of respondents & \% of respondents \\
\hline 1 & By neighbor & 12 & 12 \\
\hline 2 & Parents Decision & 22 & 22 \\
\hline 3 & Own Decision & 42 & 42 \\
\hline 4 & Others influence & 24 & 24 \\
\hline
\end{tabular}




\begin{tabular}{|l|l|l|l|}
\hline Total & 100 & 100 \\
\hline
\end{tabular}

Source: Primary data

\section{$\%$ of respondents}

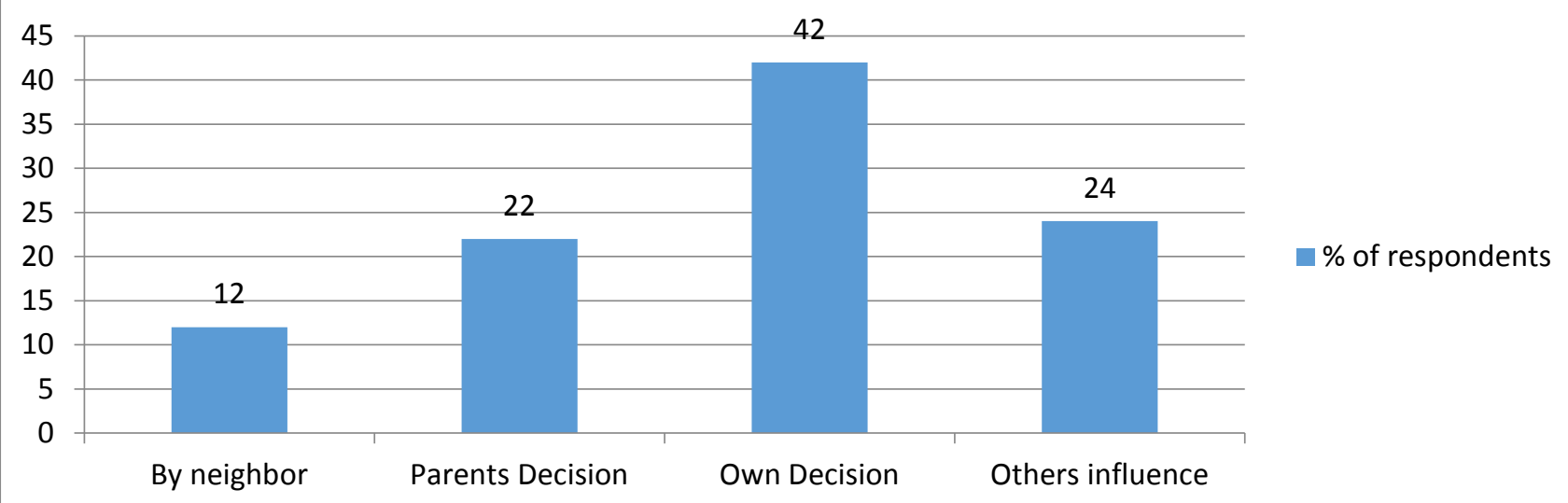

The chart and tables shows that factors influenced while choosing college by students. $12 \%$ of respondents say that neighbors' advises influenced the students to choose the college, $22 \%$ of respondents have chosen college according the wish of parents, $42 \%$ of respondents only choose their college according their own wish.

\section{3) Reasons for selection of career:}

\begin{tabular}{|l|l|l|l|}
\hline S. No & Source & No of respondents & \% of respondents \\
\hline 1 & Job vacancy & 40 & 40 \\
\hline 2 & Passion & 19 & 19 \\
\hline 3 & Goodwill & 32 & 32 \\
\hline 4 & Other & 9 & 9 \\
\hline Total & & 100 & 100 \\
\hline
\end{tabular}

Source: Primary Data

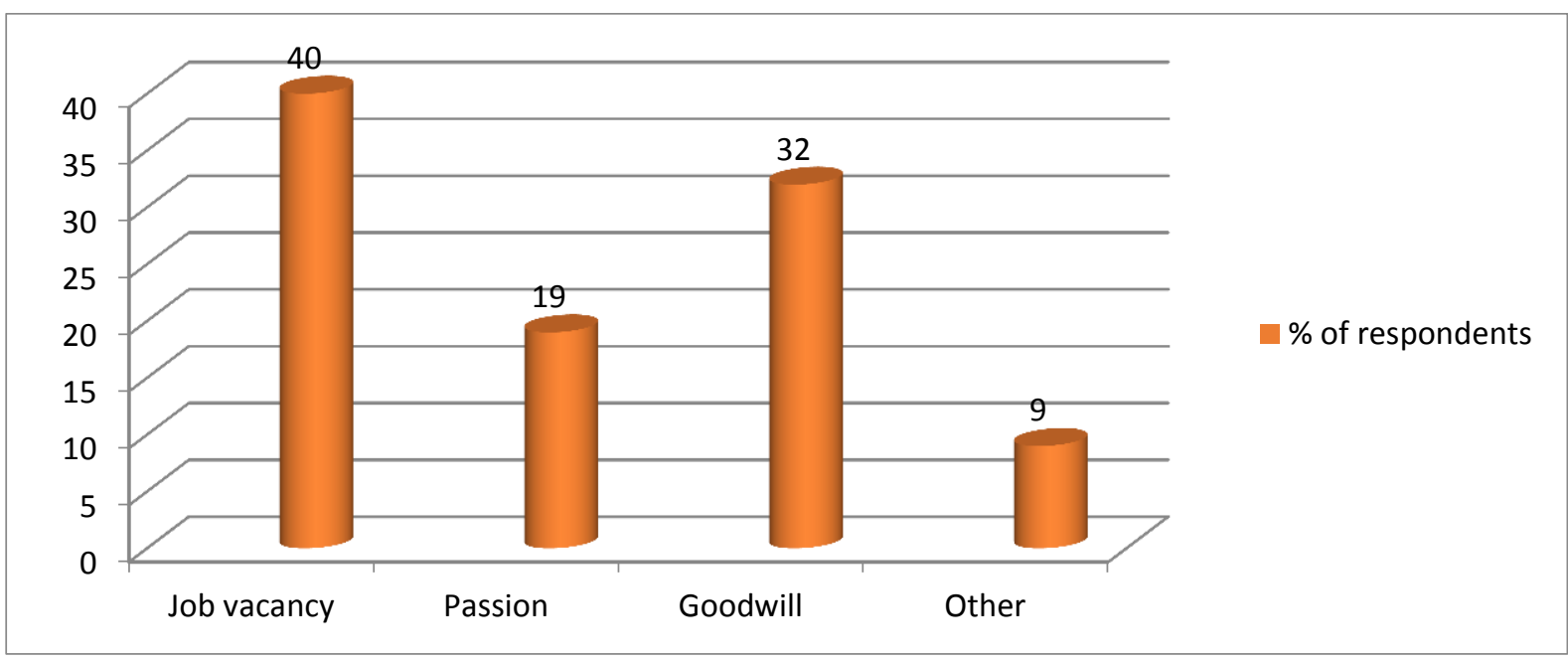


The above chart and table indicates that $40 \%$ of respondents have chosen their present career due to the existing job vacancies. $19 \%$ of respondents have passion on the selected career, the goodwill of career forced $32 \%$ respondents to select their present career.

\section{4) Satisfaction level of respondents on Selected Career:}

\begin{tabular}{|l|l|l|l|}
\hline S.No & Opinion & No of respondents & \% of respondents \\
\hline 1 & Highly Satisfied & 28 & 28 \\
\hline 2 & Satisfied & 40 & 40 \\
\hline 3 & Neutral & 12 & 12 \\
\hline 4 & Not Satisfied & 16 & 16 \\
\hline 5 & Highly not satisfied & 4 & 4 \\
\hline Total & & 100 & 100 \\
\hline
\end{tabular}

Source: Primary data

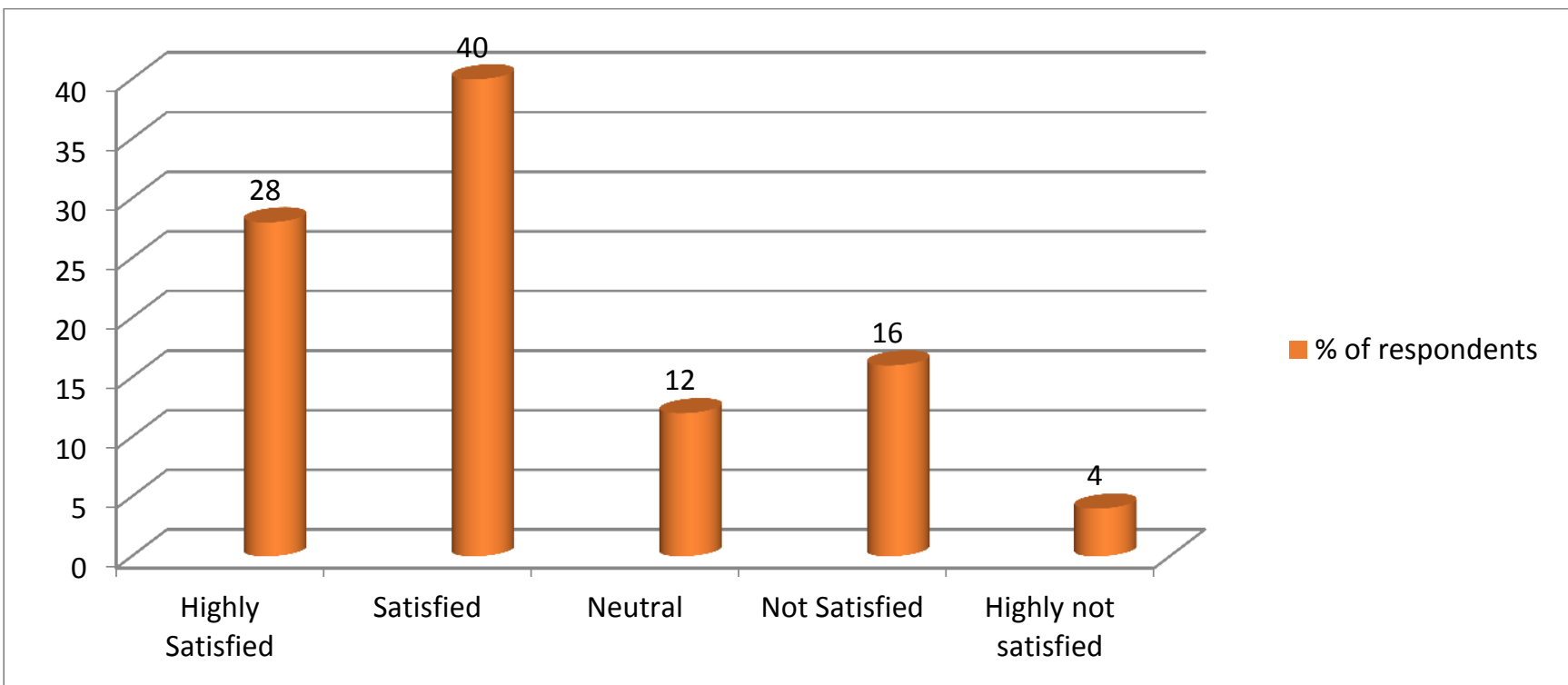

The above table and chart disclose that the satisfaction level of respondents on their selected career. $68 \%$ of respondents are satisfied on their selected career, 20\% of respondents are not satisfied on their selected career.

\section{FINDINGS}

- $38 \%$ of students are only selecting career according to their own interest and wish.62\% of students are selecting their career by the compulsion of parents, friends, relatives and neighbors.

- Career guidance classes help $76 \%$ students to select their career. 24\% respondents say that career guidance classes not influenced them to select their career.

- $12 \%$ of respondents say that neighbors' advises influenced the students to choose the college, $22 \%$ of respondents have chosen college according the wish of parents, and $42 \%$ of respondents only choose their college according their own wish. 
- $40 \%$ of respondents have chosen their present career due to the existing job vacancies. $19 \%$ of respondents have passion on the selected career, the goodwill of career forced 32 $\%$ respondents to select their present career.

- $68 \%$ of respondents are satisfied on their selected career, 20\% of respondents are not satisfied on their selected career.

- $82 \%$ of respondents have confident to achieve their goal through selected career and 18 $\%$ of respondents not have confident on selected career.

\section{SUGGESTIONS}

- Allow the students to select their interested career and avoid the parents and others compulsion on selection of career.

- Provide career guidance classes to develop knowledge and awareness about career among students in schools and colleges.

- Government should take necessary steps to increase the enrollment of students in higher studies.

- Education institution should provide the good environment and opportunities to the students to increase the confident level on career.

- Education institutions should introduce various innovative courses according to the changing employment market.

- Education system to be modified and redesigned.

\section{REFERENCES}

[1] Borchert (2002). Career choice factors of high school students. Unpublished Master of Science thesis. University of Winsconsin- Stout.

[2] Salami olufunmilayo olamide, salami oluwaseun olawaiye(2013) The factors determining the choice of career among secondary school students' The international journal of engineering and science, Volume 2 Issue 6 Pages 33-4.

[3] Choose in the Right Career-by Sajith.J.Prakash

[4] Opening of the School Education-Students aid publication

[5] Employment, Self Employment opportunities for SSLC and Plus two students-Students aid publication. 